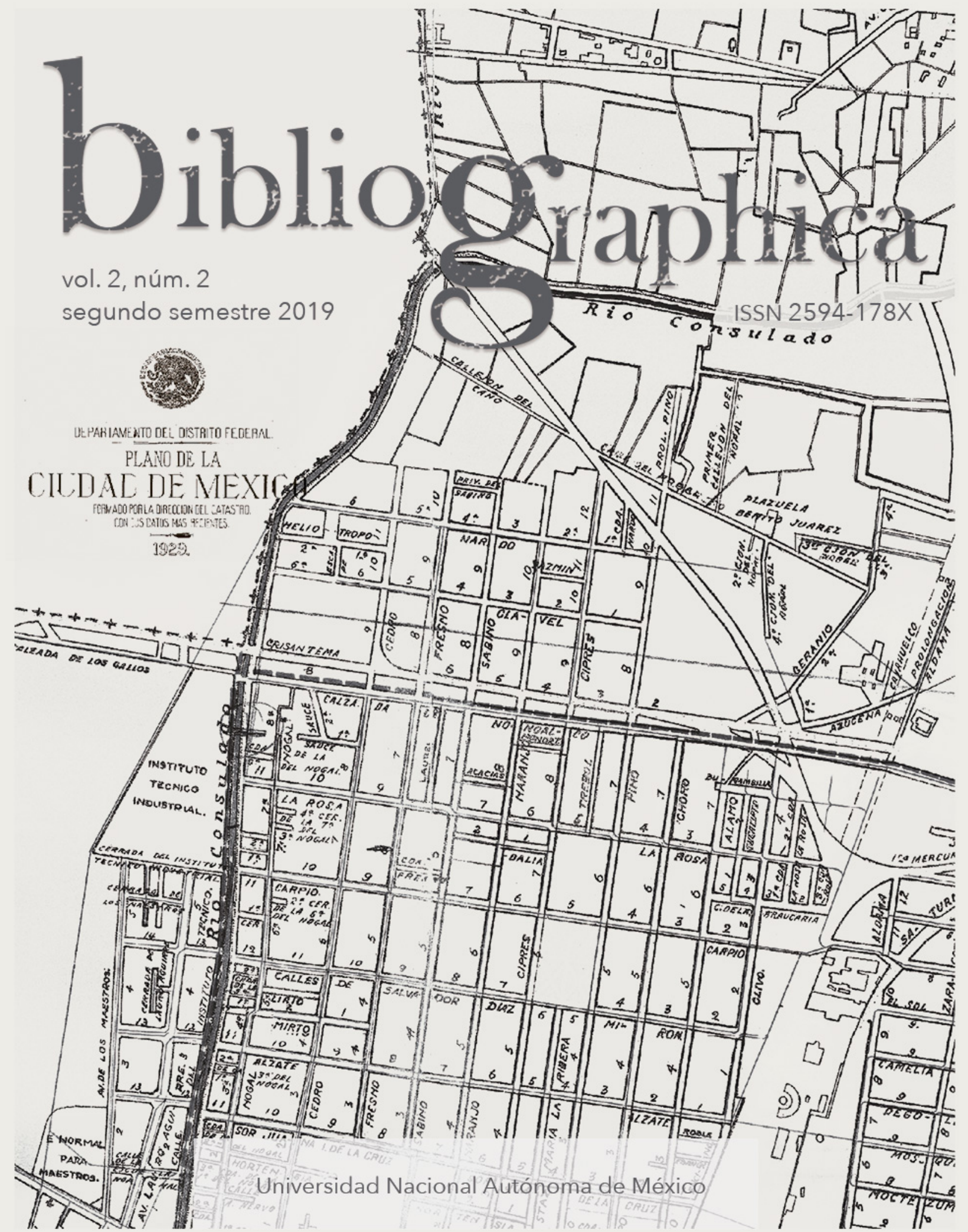




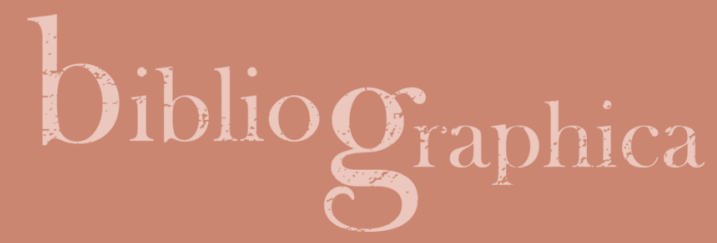

\section{Advertencia editorial}

\section{Ramona I. Pérez Bertruy}

ramonap@unam.mx

\section{Laurette Godinas}

lgodinas@unam.mx

\section{Irma Lombardo García}

irmal@unam.mx

Universidad Nacional Autónoma de México

Instituto de Investigaciones Bibliográficas

DOI: https://doi.org/10.22201/iib.bibliographica.2019.2.58 
Si la historia de la cartografía es en sí una historia de la percepción del mundo, resulta de gran importancia una mirada hacia la parte de nuestros acervos que la custodia y proyecta. En este sentido la Mapoteca de la Biblioteca Nacional de México resguarda documentos cartográficos valiosos para reconstruir la historia de las poblaciones no sólo mexicanas, sino de varios lugares del mundo, ya que representan -en plano horizontal, vertical o bidimensional- información de diversa índole: destaca la geográfica, histórica, urbana, arquitectónica, demográfica, turística, comercial y cultural. Sobresale en 1929 un Plano de la Ciudad de México formado por la Dirección del Catastro que ahora, 90 años después, ilustra la portada y banner del presente número de Bibliographica.

Este plano a color mide $130 \times 174 \mathrm{~cm}$, con escala de 1:10 000; lo mandó elaborar el médico José Manuel Puig Casauranc cuando era jefe del Departamento del Distrito Federal, y fue preparado por la Oficina de Catastro -cuyo responsable era Francisco Rodríguez del Campo- para dar a conocer la expansión urbana que tendría la ciudad a partir de la promulgación de la Ley Orgánica del Distrito y de los Territorios Federales, el 31 de diciembre de 1928. El plano muestra la nueva delimitación del Departamento Central, ya que desde el 10. de enero de 1929 la antigua municipalidad de la Ciudad de México más las de Tacuba, Tacubaya y Mixcoac, así como parte de Iztapalapa, Guadalupe Hidalgo y Azcapotzalco, pasaron a formar parte del Departamento Central.

La Ciudad de México se constituyó así en cabecera del Departamento Central, del Distrito Federal y de la república mexicana. ${ }^{1}$ Con afán de mostrar el engrandecimiento urbano, comercial y cultural de la capital nacional al unírsele los núcleos de Tacuba y Tacubaya, aparecen en este plano los lugares más notables y los edificios públicos de instituciones políticas, científicas, culturales, de servicios y recreativas. De igual manera, pretende mostrar el adelanto que había alcanzado la sede metropolitana en materia de infraestructura hidráulica, especialmente en cuanto a la red de saneamiento y agua potable. Indica, además, ríos y canales, con el propósito de señalar lo poco que quedaba del viejo sistema hidrológico de la cuenca del valle de México.

El plano examinado se encuentra plegado al segundo volumen del Atlas general del Distrito Federal, obra de 1930 publicada en dos tomos por los Ta-

\footnotetext{
${ }_{1}^{1}$ Atlas general del Distrito Federal geográfico, histórico, comercial, estadístico, agrario: su descripción más completa, profusamente ilustrada con mapas, fotografías y gráficas: se formó por orden del señor doctor José M. Puig Casauranc, Jefe del Departamento del Distrito Federal en la oficina del Catastro, en 1929 siendo jefe de ella el señor F. Rodríguez del Campo, vol. 1 (México: Talleres Gráficos de la Nación, 1930), 57, 99.
} 
lleres Gráficos de la Nación. El objetivo de esta edición oficial de gran formato fue anunciar una nueva faceta del Distrito Federal, la cual expone claramente el director del Catastro. En las páginas preliminares comenta Francisco Rodríguez del Campo que no se trata de un estudio exhaustivo sobre la historia y geografía del Distrito Federal, sino de una "breve descripción histórica de sus pueblos y habitantes, de su organización política y de sus sistemas administrativos y sociales; los antecedentes y la resolución del problema agrario y una serie de datos estadísticos y de ilustraciones fotográficas que interesarán por igual a los turistas, a los hombres de negocios y al público en general". ${ }^{2}$

El primer tomo está dedicado a la reseña geográfica e histórica, la estructura política con su oferta educativa, científica, artística y cultural, abundantemente ilustrado con fotografías de monumentos notables; el segundo contiene los planos históricos y actuales de la Ciudad de México, el del Distrito Federal (escala 1:50 000) e incluye los de las nuevas delegaciones (escala 1:10 000) que lo conforman. "El Plano del Distrito Federal (a color, de $93 \times 133 \mathrm{~cm}$ ) señala la mancha en rojo y con signos convencionales, vías de ferrocarriles y tranvías, caminos, ríos y canales, acueductos, poblados y límites delegaciones"; ${ }^{3}$ estos últimos se refieren a las viejas municipalidades que a partir de 1929 adquirieron el estatus de delegaciones, a saber: Azcapotzalco, Coyoacán, Cuajimalpa, General Anaya, Guadalupe Hidalgo, Ixtacalco, Iztapalapa, La Magdalena Contreras, Milpa Alta, San Ángel, Tláhuac, Tlalpan y Xochimilco. Dichos planos a color de 33 x $45 \mathrm{~cm}$ muestran la nueva delimitación político-administrativa de las 13 delegaciones y marcan tanto la zona urbana y los accidentes geográficos como los servicios de alumbrado, pavimentación, agua potable, saneamiento, áreas verdes, mercados, panteones, edificios y vías de comunicación (tranvías y ferrocarriles).

El Atlas también pondera el hecho de que, desde 1929, el presidente de México tendría a su cargo la administración del Departamento del Distrito Federal (DDF), que a la vez ejercería sus funciones a través de las siguientes dependencias: Obras Públicas, Hacienda, Gobernación, Acción Cívica, de Reforma, Recreativa y Social, Policía y Seguridad, Tesorería General, Catastro y Consultiva.

Los planos que conforman esta obra fueron elaborados con las técnicas de precisión más modernas -a partir de tomas fotográficas aéreas- para "dar una impresión lo más real posible del territorio que describe[n]", mediante un regis-

\footnotetext{
${ }^{2}$ Ibid., 13.

${ }^{3}$ Alejandrina Escudero, "La ciudad posrevolucionaria en tres planos. The Post-revolucionary City in Three Plans", Anales del Instituto de Investigaciones Estéticas 93 (2008): 7, acceso el 21 de junio de 2019, http//dx.doi.org/10.22201/iie.18703062e.2008.93.2276.
} 
tro topográficamente veraz del espacio y con sus detalles urbanos, comercio, agrarismo, instituciones sociales, etcétera, ${ }^{4}$ al tiempo que sirvieron para mostrar -ante propios y extraños- el desarrollo logrado por las poblaciones del Distrito Federal. De acuerdo con las palabras de una experta en la materia:

el Atlas reunía la más vasta y actualizada información de ese territorio hasta el momento. Aunque tiene mucho en común con las guías de viajeros que proporcionaban todos los datos posibles sobre la ciudad y sus alrededores, en realidad pretendía ofrecer una apología del estado que guardaban la Ciudad de México y el Distrito Federal, avalada con documentos oficiales (relativos a censos, estadísticas, topografía y asuntos económicos, entre otros), bibliografía y un señalado despliegue gráfico.

La especialista en cartografía lo coloca en su justa dimensión al afirmar que es:

la obra bibliográfica sobre el tema más ambiciosa del periodo; íntimamente relacionado con la nueva organización político-administrativa y su discurso, ubica a la Ciudad de México y al Distrito Federal en un momento culminante de su desarrollo; este discurso, por un lado, se apoya en el pasado -historia, toponimia, heráldica, etc.- y, por otro, la compara con las avanzadas metrópolis extranjeras. ${ }^{5}$

En este contexto el plano representa, sin duda, la memoria de una faceta de la Ciudad de México posrevolucionaria donde se anuncia una nueva relación entre ésta y el jefe del DDF. "Y lo más importante: el afán de dotar a esa capital de una infraestructura urbana integral y de solucionar sus problemas de conjunto". ${ }^{6}$ Asimismo, apunta el comienzo de una urbe hacia la megalópolis que conocemos en la actualidad, marcada por una desmedida y acelerada expansión.

Queda en manos de los lectores de Bibliographica la renovada muestra de un fragmento rescatado de esta cartografía representativa de la historia contemporánea de la Ciudad de México, gracias al profesional y artístico diseño elaborado por Hilda Maldonado y Carolina Silva Bretón.

\footnotetext{
${ }^{4}$ Atlas general del Distrito Federal, 13.

${ }^{5}$ Escudero, "La ciudad posrevolucionaria en tres planos", 6, 7.

${ }^{6}$ Ibid., 5.
} 